\title{
POTENTIAL GENDER DIFFERENCES IN PATHOPHYSIOLOGY OF MIGRAINE AND TENSION TYPE HEADACHE
}

\author{
Restu Susanti ${ }^{1)}$ \\ ${ }^{1}$ Fakultas Kedokteran, Universitas Andalas, RSUP Dr. M.Djamil Padang, Jl.Perintis Kemerdekaan, Sawahan \\ Timur, Padang Timur, Kota Padang \\ email: restususanti@yahoo.com
}

Submitted: 30-03-2020, Reviewer: 30-03-2020, Accepted: 07-04-2020

\begin{abstract}
Headache is one of the most common symtomps which cause patients consult a neurologist. Primary headache is headache without other underlying diseases. Primary headaches can be divided into migraine headaches, tension types-headache, trigeminal autonomic cephalalgias, and other types of headaches. Sex differences play a role in the perception of headache. Theories regarding hormonal, the number of pain-sensitive points, subjectivity, and psychosocial factors are mostly related to the differences of migraine and TTH pathophysiology between women and men.
\end{abstract}

Keywords: migraine, tension-type headache, women

\begin{abstract}
Abstrak
Nyeri kepala merupakan salah satu keluhan yang sering menjadi alasan pasien datang berobat. Nyeri kepala primer adalah nyeri kepala tanpa penyakit lain yang mendasarinya. Nyeri kepala primer dibedakan menjadi migren, tension type-headache, trigeminal autonomic cephalalgias dan nyeri kepala tipe lainnya. Perbedaan jenis kelamin berperan dalam persepsi nyeri kepala. Teori mengenai hormonal, jumlah titik peka nyeri, subjektivitas, dan faktor psikososial banyak dikaitkan dengan patofisiologi perbedaan migren dan TTH antara perempuan dan laki-laki.
\end{abstract}

Kata Kunci :migren, tension type headache, perempuan

\section{PENDAHULUAN}

Nyeri kepala merupakan salah satu keluhan yang sering menjadi alasan pasien datang berobat. Klasifikasi nyeri kepala primer yang digunakan saat ini berdasarkan ICHD-3 (International Classification of Headache Disorders). Nyeri kepala primer dibagi menjadi 4 yaitu migren, nyeri kepala tipe tegang (tension type-headache), Nyeri kepala trigeminal otonom (trigeminal autonomic cephalalgias) atau nyeri kepala klaster dan nyeri kepala tipe lainnya ${ }^{[1,2]}$

Secara umum, persepsi nyeri berubah seiring pertambahan usia. Persepsi nyeri kepala akan berbeda antar usia muda dan usia lanjut ${ }^{[3]}$. Perbedaan jenis kelamin juga berperan dalam persepsi nyeri kepala. Perempuan lebih sering mengeluhkan nyeri kepala dibanding laki-laki. Ada beberapa teori terkait nyeri kepala primer dan hubungannya dengan jenis kelamin. Hubungan hormonal merupakan salah satu fokus utama beberapa penelitian yang masih terus dikembangkan saat ini. Selain itu subjektivitas nyeri juga lebih tinggi pada perempuan yang diduga berhubungan juga dengan psikososial ${ }^{[4]}$.

Beberapa data menunjukkan migren merupakan salah satu nyeri kepala primer yang paling banyak dikeluhkan perempuan dibandingkan laki-laki. Sedangkan untuk nyeri kepala kronik seperti nyeri kepala klaster lebih banyak dikeluhkan oleh lakilaki ${ }^{[5]}$. Sehingga menarik untuk membahas lebih lanjut tentang nyeri kepala primer khususnya migren dan tension-type headache yang masing-masing kaitannya 
dengan perempuan sehingga menambah pemahaman mengenai nyeri kepala primer pada perempuan terutama dalam hal patofisiologi.

\section{NYERI KEPALA MIGREN (MIGRAINE HEADACHE)}

\section{Klasifikasi Migren:}

a. Migren tanpa aura Unilateral,berdenyut, intensitas nyeri sedang hingga berat, diperberat dengan aktivitas seperti berjalan atau menaiki tangga. Keluhan nyeri diikuti salah satu keluhan mual atau fotofobia maupun fonofobia. Keluhan nyeri kepala berlangsung 4-72 jam.

b. Migren dengan aura

Selain memenuhi kriteria migren tanpa aura, migren dengan aura harus memenuhi kriteria adanya salah satu aura (visual, sensorik, biacara, motoirik, brain stem, retinal) yang sifatnya reversible. Aura tersebut berlangsung selama 5-60 menit.

i. Migren dengan aura tipikal. Aura yang muncul adalah aura visual, sensorik dan atau bahasa. Tidak ada gejala motorik, brain stem atau retinal.

ii. Migren dengan aura brainstem. Aura yang muncul pada tipe migren ini adalah disartria, vertigo, tinnitus, hypacusis, diplopia, ataksia, penurunan kesadaran dengan GCS $\leq 13$. Tidak ada gejala motorik maupun retinal.

iii. Migren hemiplegik. Gejala migren disertai dengan kelemahan anggota gerak, gangguan visual, sensorik dan atau berbahasa.

c. Migren kronik

Nyeri kepala berlangsung $\geq 15$ hari per bulan selama $>3$ bulan yang memenuhi kriteria migren dengan atau tanpa aura

\section{Patofisiologi Migren dan Hubungannya dengan Perempuan}

Peran hormon seks lebih sering ditemukan pada kasus nyeri kepala migren. Frekuensi nyeri kepala migren pada anak usia pre-pubertas sekitar 3-10\%. Memasuki usia pubertas, akibat perubahan hormonal, frekuensi nyeri kepala semakin meningkat dengan angka kejadian lebih sering 2-3 kali lipat pada perempuan dibanding pada lakilaki yang membuktikan bahwa perubahan status hormonal sangat berperan terhadap kejadian migren. Termasuk didalam perubahan hormonal ini adalah menarche, menstruasi, kehamilan, menopause, dan juga penggunaan kontrasepsi hormonal baik oral maupun hormonal replacement theraphy ${ }^{[6]}$.

Migren menyerang perempuan 3 kali lebih sering dibanding laki-laki. Migren semakin sering muncul pada 1-2 tahun sebelum atau sesudah menarche, dimana sebuah penelitian oleh Maleki tahun 2017 menunjukkan kecenderungan menderita migren di usia menarche akan mengalami migren dikemudian hari ${ }^{[6]}$. Puncak usia menderita migren pada perempuan setelah pubertas sekitar 30 hingga 39 tahun $^{[7]}$.

Ada beberapa teori yang diajukan dalam memahami mekanisme penyebab migren dari segi perbedaan jenis kelamin. Teori yang paling sering digunakan adalah perubahan hormon seksual terutama pada perempuan sebagai pencetus migren. Hormon perempuan terutama estrogen mengalami fluktuasi selama masa kehidupan perempuan sesuai dengan siklus alami hormonal, yang dapat memicu migren.

Dibandingkan dengan laki-laki, perempuan memang lebih sering datang ke praktek dokter dengan keluhan migren dan gejala yang menyertai migren seperti fotofobia, 
fonofobia, mual, aura visual ataupun pandangan kabur ${ }^{[6]}$.

Beberapa faktor telah teridentifikasi meningkatkan resiko migren, dari migren episodik menjadi migren kronik, yaitu lingkungan, genetik dan faktor sosial. Migren pada perempuan sangat beresiko tinggi menjadi migren kronik karena kejadian depresi yang tinggi, kecemasan yang berlebihan bahkan pengalaman tidak menyenangkan pada masa kecil ${ }^{[8]}$.

Perempuan dengan obesitas juga beresiko 2 kali lebih sering mengalami migren episodik maupun migren kronik, hal ini diduga berhubungan dengan produksi estrogen yang patologis pada jaringan adiposa.

Estrogen withdrawal berperan sebagai pemicu migren dan hal ini dikonfirmasi melalui sebuah penelitian terhadap hewan coba yang menunjukkan hormon gonadotropin perempuan meningkatkan resiko migren melalui efek elektrofisiologi estrogen-dependent.Sebaliknya, mekanisme testosteron pada migren masih belum diketahui pasti, diduga testosteron berperan dalam modulasi aliran darah otak, serotonergic tone, dan diduga juga pada cortical spreading depression ${ }^{[9]}$.

Serotonin dianggap memiliki peranan penting dalam patogenesis migren, dimana serotonin sendiri produksinya ditingkatkan oleh peran estrogen, yang akan meningkatkan ekspresi trytophan hydroxylase dan menurunkan ekspresi serotonin re-uptake transporter. Estrogen juga diaktivasi oleh sistem opioid endogen yang menghasilkan efek analgesik. neurogenik dan sekresi histamin dari sel mast dengan menurunakan produksi prostaglandin $^{[8]}$.

Sebuah penelitian tentang progesteron menunjukkan bahwa progesteron berperan dalam mengurangi nosisiptif sistem trigemino vaskular melalui penghambatan edema.

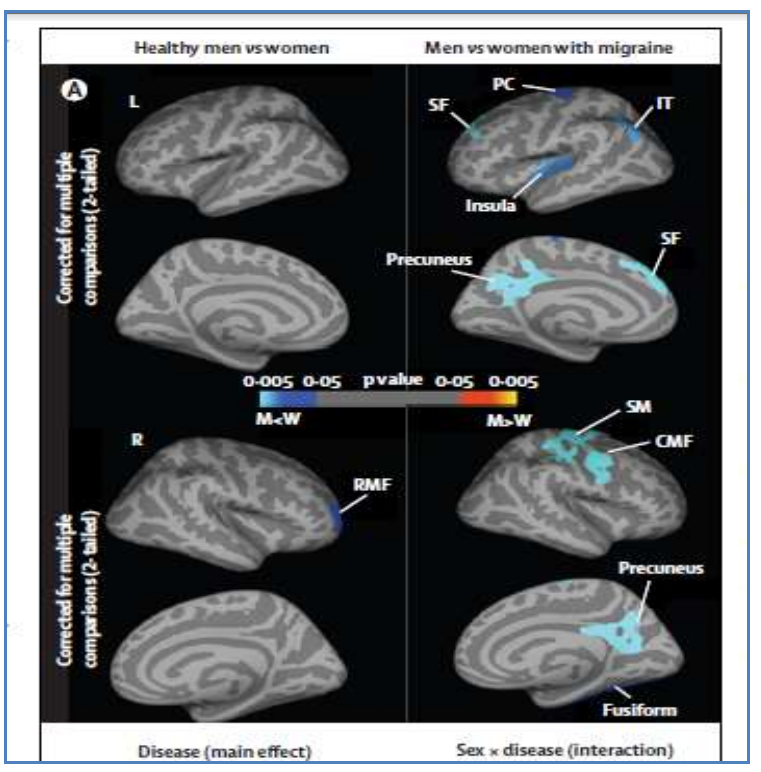

Gambar 1. Ketebalan korteks pada pasien dengan migren, sisi kiri adalah gambaran pada lakilaki dan perempuan yang sehat, sisi kanan menggambarkan laki-laki dan perempuan dengan migren. Warna biru muda menunjukkan area korteks lebih tebal pada perempuan ${ }^{[10]}$.

Pemeriksaan pencitraan baik strutural, kimiawi maupun fungsional juga ditemukan perbedaan pada perempuan dengan migren ibanding dengan laki-laki. Perbedaan ini berkaitan dengan proses nyeri, sensasi, afektif dan fungsi otonom termasuk didalamnya penebalan insula sinisitra bagian posterior dan peningkatan aktivitas insula $^{[8,12]}$. Peningkatan aktivasi pada proses emosi juga ditemukan lebih sering terjadi pada perempuan dibanding laki-laki, menunjukkan kemungkinan mekanisme seorang perempuan penderita migren memiliki subjektivitas lebih tinggi dalam menggambarkan perasaan nyeri yang dialaminya ${ }^{[10,8]}$.

\section{NYERI KEPALA TIPE TEGANG (TENSION-TYPE HEADACHE)}

\section{Klasifikasi Tension-Type Headache (TTH) $)^{1,2}$}

a. TTH Infrekuen

Lokasi nyeri kepala bilateral seperti ditekan dan berat (tidak berdenyut. 
Serangan ringan hingga sedang. Tidak dipengaruhi dengan aktivitas seharihari. Tidak ada muntah amaupun mual Serangan nyeri kepala minimal 10 episode dalam 1 bulan berlangsung 30 menit-7 hari.

b. TTH Frekuen

Deskripsi nyeri seperti TTH infrekuen namun frekuensi serangan 10 episode dengan rata-rata $>12$ hari per bulan.

c. TTH kronik

Keluahan seperti TTH infrekuen dan frekuen namun nyeri berlangsung $>15$ hari per bulan, tiap episode serangan berlnagsung beberapa jam hingga beberapa hari atau tidak ada fase remisi.keluhan tanpa mual, muntah, fotofobia maupun fonofobia.

\section{Patofisologi Tension-Type Headache dan Hubungannya dengan Perempuan}

Tension-type headache merupakan nyeri kepala primer dengan angka kejadian $42 \%$ dari seluruh jenis nyeri kepala primer $^{[11]}$. Berdasarkan jenis kelamin, TTH 1,5 kali lipat lebih sering terjadi pada perempuan dibanding laki-laki. Sedangkan nyeri kepala klaster sebaliknya, lebih sering terjadi pada laki-laki terutama usia remaja dan paruh baya. Seiring bertambahnya usia, angka kejadian nyeri kepala klaster tidak berbeda secara signifikan antara laki-laki maupun perempuan ${ }^{[12]}$

Patogenesis mengenai TTH saat ini difokuskan pada peran jaringan otot dan proses propioseptif terhadap nyeri. Terdapat anggapan bahwa peran komponen otot berkontribusi dalam proses sensitisasi nyeri yang berhubungan dengan perubahan TTH dari akut menjadi kronik ${ }^{[13,14]}$.Terdapat bukti bahwa penderita TTH mengalami hipersenstivitas nyeri pada nyeri yang sebenarnya ringan pada beberapa titik yaitu daerah trigeminal, area servikal, area diluar trigeminal. Nyeri juga dirasakan menjalar saat titik otot tertentu dirangsang yang diduga merupakan peran dari saraf perifer terhadap kejadian TTH yang disebut triger points $(\operatorname{Tr} P s)^{[15]}$.

Triger points adalah titik hipersensitif pada hubungan antara otot yang menimbulkan rasa nyeri menjalar, dan gejala motorik saat diberikan stimulasi ${ }^{[16]}$. Beberapa penelitian mengatakan bahwa rasa nyeri menjalar yang dicetuskan oleh $\operatorname{TrPs}$ menghasilkan pola nyeri yang khas pada pasien dengan $\mathrm{TTH}^{[17]}$. Penelitian oleh delas-Penas, dkk mengatakan bahwa bentuk nyeri dimana $\operatorname{Tr} P$ s pada otot yang diinervasi oleh $n$. trigeminal atau $n$. cervical bagian atas bertanggung jawab terhadap nyeri nosiseptif yang terus menerus, mesensitisasi sistem saraf pusat dan pada akhirnya menyebabkan widespread sensitization pada $\mathrm{TTH}^{[15]}$. Sensasi nyeri tersebut telah dikonfirmasi ulang oleh penelitian terbaru yang melaporkan bahwa lebih banyak $\operatorname{TrPs}$ pada kepala, leher, dan otot bahu berhubungan dengan hipersentivitas nyeri tekan pada individu dengan TTH. Jumlah $\operatorname{TrpS}$ yang aktif ini secara tidak langsung juga berhubungan dengan tingkat kecemasan yang juga menjadi faktor yang berperan pada proses sensitisasi sentral dengan mengurangi ambang noxious input dari otot perikranial $^{[18,19]}$.

Sejak adanya bukti bahwa jenis kelamin berperan dalam persepsi nyeri terutama sensitivitas terhadap nyeri tekan, perkembangan struktur dan fungsi otak, pengalaman hidup sebelumnya, kultur budaya dan faktor biopsikososial yang berhubungan dengan pengalaman nyeri, menjadikan seorang klinisi dapat menentukan program terapi yang tepat sesuai dengan jenis kelamin ${ }^{[20]}$.

Penelitian oleh Mendez MC, dkk pada tahun 2019 tentang TrPs, menunjukkan bahwa perempuan memiliki jumlah $\operatorname{Tr} P s$ aktif yang jauh lebih banyak dibanding lakilaki terutama di sub-oksipital, temporal, otot splenius. Jumlah TrPs aktif ini diduga 
memang diakibatkan perbedaan struktur otot bawaan antara laki-laki dan perempuan. Jumlah $\operatorname{Tr} P$ s aktif ini juga berbanding lurus terhadap tingkat ansietas pasien dengan TTH. Penelitian sebelumnya mengatakan tingkat kecemasan berhubungan dengan muscular tenderness ${ }^{[21]}$. Pada kenyataannya stres pada umumnya merupakan salah satu faktor resiko nyeri timbul. Terdapat bukti bahwa perempuan memiliki tingkat ansietas lebih tinggi diabanding laki-laki $(1,8: 1)^{[22]}$.

Penelitian lainnya juga menunjukkan bahwa ambang batas nyeri yang rendah pada perempuan dibanding laki-laki sehingga perempuan lebih sensitif terhadap rasa nyeri terutama pressure pain dan aktivasi modulasi analgesia berkurang pada perempuan $^{[17]}$.

\section{KESIMPULAN}

Nyeri kepala primer berupa migren dan TTH merupakan nyeri kepala yang frekuensinya tinggi pada perempuan dibanding laki-laki. Nyeri kepala primer lainnya berdasarkan data epidemiologi lebih sering terjadi pada laki-laki, contohnya nyeri kepala klaster.

Migren erat hubungannya dengan kondisi hormonal. Peran hormon sangat nyata untuk menimbulkan sensasi nyeri. Sedangkan pada TTH, mekanisme nyeri lebih disebabkan karena adanya titik peka nyeri yang secara alami lebih banyak ditemukan pada perempuan dibanding lakilaki sehingga resiko perempuan mengalami TTH jauh lebih tinggi dibanding laki-laki.

Faktor lain yang turut berperan terhadap migren dan TTH antara lain faktor stres, ansietas berlebihan, yang tidak dapat dipungkiri menaikkan ambang batas nyeri sehingga perempuan menjadi lebih peka terhadap rasa nyeri dibanding laki-laki.

\section{KEPUSTAKAAN}

1. Headache Classification Committee of the International Headache Society (IHS). The International Classification of Headache Disorders, 3rd edition. Cephalalgia. 2018;38:1-211.

2. Kelompok Studi Nyeri Kepala, PERDOSSI. Konsensus Nasional V. Diagnostik dan Penatalaksanaan Nyeri Kepala. 2018. Hal 13-37

3. El Tumi H, Johnson MI, Dantas PBF, Maynard MJ, Tashani OA. 2017. Age related changes in pain sensitivity in healthy humans: a systematic review with meeta-analysis. EurJ Pain.Vol 21(6): 955-64.

4. Lautenbacher S, Peter JH, Heesen M, Scheel J, Kunz M. 2017. Age changes in pain perception: a systematic review and meta-analysis of age effects on pain and tolerance thresholds. Neurosci Biobehav rev. Vol 75:104-13.

5. Woldeamanuel YW, Andreou AP, Cowan RP. 2014. Prevalence of migraine headache and ots woght on neurological burden in africa: a 43-year systematic review and meta-analysis of community based studies.J Neurol Sci. Vol 324.pp:1-15

6. Lagman-Bartolome AM, Lay C. Migraine in Women. Neurol Clin. 2019 Nov;37(4):835-45.

7. Pavloic JM, Akcali D, Bolay H. 2017. Sex-related influences in migraine. $J$ Neurosci Res. Vol:95.p:587.

8. Schroeder RA, Brandes J, Buse DC, Calhoun A, Eikermann-Haerter K, Golden K, et al. Sex and Gender Differences in Migraine-Evaluating Knowledge Gaps. J Womens Health (Larchmt). 2018 Aug;27(8):965-73.

9. Pavloic JM, Vieira JR, Lipton RB, Bond DS. 2017. Association between obseity and migriane in women. Curr Pain and Headache 
10. Vetvik KG, Mc Gregor EA. 2016. Sex differences in the epidemiology, clinical features and pathophysiology of migraine. The Lancet of Neurology.

11. Mendez MC, Antona CJ, Paras PB, Novo SF, Jimenez JR, De-Las Penas CF. 2019. Active trigger points are associated with anxiety and widespread pressure pain sensitivity in women, but not men, with tension type headache. Pain Practice. Vol.19(5):522-9.

12. Dellaruelle Z, Ivanova TA, Khan S, Negro A, Omelo R, Raffaelli B, et al. 2018. Male and female sex hormones in primary headaches. The journal of Headache and Pain. Vol 19:117.

13. Arendt-Nielsen L, Castaldo M, Mechelli F, Fernández-de-las-Peñas C. Muscle Triggers as a Possible Source of Pain in a Subgroup of Tension-type Headache Patients? Clin J Pain [Internet]. 2016;32(8).

14. de Tommaso M, Fernandez-de-LasPenas C. Tension Type Headache. Curr Rheumatol Rev. 2016;12(2):127-39

15. Fernández-De-Las-Peñas C, FernándezMuñoz JJ, Palacios-Ceña M, ParásBravo P, Cigarán-Méndez M, NavarroPardo E. Sleep disturbances in tensiontype headache and migraine. Ther Adv Neurol Disord. 2018;11:1-6.

16. Simons DG, Travel JG, Simons. 2019. Myofascial pain and dysfunction. The trigger Point Manual 3rd edition.

17. Abboud J, Marchand AA, Sorra K, Descarreaux M. 2013. Musculoskeletal physical outcome measures in individuals with tension-type headache: a scoping review. Cephalalgia. Vol 33:1319-36.

18. Palacious-Ceria M, Castaldo M, Wang K. 2017. Relationship of trigger points with related disability and anxiety in people with tension-type headache. Medicine. Vol 96:6548.
19. Palacious-Ceria $\mathrm{M}$, Wang $\mathrm{K}$, castaldo M. 2018.Trigger points are associated with widespread pressure pain sensitivity in people with tension-type headache. Cephalalgia. Vol 38: 237-45.

20. Racine M, Tousignant-Laflamme Y, Kloda LA, Dion D, Dupuis G, Choiniere M. 2012. A systematic literature review of 10 years on sex/gender and pain perception Part 2: do biopsychososcial alter pain sensitivity differenty in women and men?. Pain. Vol 153:619-35.

21. Ingalhalikar M, Smith A, pareker D. 2014. Sex differences in the structural connecntions of the human brains. PNAS. Vol 111:823-28.

22. Lampl C, Thomas H, Tassoreli C. 2016. Headache, depression and anxiety: associations in the Eurolight project. $J$ Headache Pain. Vol 17:59. 